\title{
Atividade fungitóxica de extratos de Piper sp. contra os fungos Rhizoctonia solani e Sclerotium rolfsii
}

\begin{abstract}
A busca por mecanismos que podem ajudar no controle de fitopatógenos tem sido recorrente, tendo como fonte a diversidade biológica, dada à sua variabilidade, fornecendo compostos com ação farmacológica diversa, tal qual no combate de microrganismos. Estudos relatam o uso de extratos contra os fungos fitopatogênicos com o objetivo de manter um equilíbrio destes patógenos, por estes causarem grandes danos em diversas culturas agrícolas. Por tanto este trabalho tem como objetivo testar extratos de Piper sp. contra os fungos Rhizoctonia solani e Sclerotium rolfsii, patógenos de extrema importância na cultura do feijoeiro. Desta forma, foram coletadas na casa de vegetação da Embrapa Rondônia, talos e folhas de Piper sp. e, após sua maceração, em solução extratora tampão PBS 0,1 M obteve-se os extratos, na proporção 1:10 (p/v, g/mL). Os extratos foram adicionados ao meio BDA semissólido na proporção 1/100 (V/V) maceração, em solução extratora tampão PBS $0,1 \mathrm{M}$ obteve-se os extratos, na proporção $1: 10(\mathrm{p} / \mathrm{v}, \mathrm{g} / \mathrm{mL})$. Os extratos foram adicionados ao meio BDA semissólido na proporção $1 / 100$ (V/V)
sendo em seguida homogeneizados e vertidos em placas de petri. No centro das placas, discos de micélio dos patógenos foram depositados, sendo vedadas e incubadas em câmara B.O.D. por até $96 \mathrm{~h}$, sob condições controladas de temperatura e fotoperíodo de $12 \mathrm{~h}$. A atividade antifúngica dos extratos também foi avaliada em experimento in vivo, conduzido em casa de vegetação. Para tanto, plântulas de feijoeiro foram inoculadas com os patógenos e testadas com diferentes concentrações dos extratos de Piper sp. Foram avaliadas 6 concentrações, com 5 repetições por tratamento. Como controles foram usados tampão PBS 0,1 M e os fungicidas Amistar e Vitavax, conforme recomendação do fabricante. As avaliações foram realizadas diariamente, a partir do segundo dia de incubação, nas quais foram feitas as medições do halo de crescimento dos fungos, por meio de um paquímetro, até que a medição das placas que continham o grupo controle com PBS atingissem a borda das mesmas. Dos extratos testados, o extrato de talo promoveu inibição do crescimento de R. solani estatisticamente superior a efeito do fungicida comercial, enquanto que contra S. rolfsii, embora o extrato tenha sido eficiente, o efeito foi inferior ao do fungicida testado. Este trabalho permite inferir que extratos de Piper sp. apresentaram atividades significativas contra os fungos Rhizoctonia solani e Sclerotium rolfsii. Novos testes serão realizados para verificar sua eficiência in vivo (campo).
\end{abstract}

Palavras-chave: Extratos; Atividade Fungitóxica; Fitopatógenos.

\section{Fungicidal activity of extracts of Piper sp. against fungi Rhizoctonia solani and Sclerotium rolfsii}

\begin{abstract}
The search for mechanisms that may help in the control of phytopathogens has been recurrent, having as a source the biological diversity, due to its variability, providing compounds with diverse pharmacological action, such as in the fight against microorganisms. Studies report the use of extracts against phytopathogenic fungi in order to maintain a balance of these pathogens, as they cause great damages in several agricultural crops. Therefore, this work aims to test extracts of Piper sp. against the fungi Rhizoctonia solani and Sclerotium rolfsii, pathogens of extreme importance in the bean crop. In this way, stems and leaves of Piper sp. were collected in the greenhouse of Embrapa Rondônia. Extracts, in the proportion 1:10 (w/v, g/mL), were extreme importance in the bean crop. In this way, stems and leaves of Piper sp. were collected in the greenhouse of Embrapa Rondonia. Extracts, in the proportion $1: 10$ ( $\mathrm{W} / \mathrm{V}, \mathrm{g} / \mathrm{mL}$ ), were center of the plates, mycelial discs of the pathogens were deposited, being sealed and incubated in chamber B.O.D. for up to 96 hours, under controlled temperature and photoperiod center of the plates, mycelial discs of the pathogens were deposited, being sealed and incubated in chamber B.O.D. for up to 96 hours, under controlled temperature and photoperiod
conditions. Fungal growth evaluations were performed daily, using a pachymeter, from the second day of incubation until control group plates measurement, with PBS buffer, reached total growth. The antifungal activity of the extracts was also evaluated in an in vivo experiment conducted under greenhouse conditions. For that, bean seedlings were inoculated with the pathogens and tested with different concentrations of Piper sp. Six concentrations were evaluated, with 5 replicates per treatment. As controls, 0.1 M PBS buffer and Amistar and Vitavax fungicides were used, as recommended. From the extracts tested, stem extract promoted inhibition of R. solani growth statistically superior to that of the commercial fungicide, whereas against S. rolfsii, although the extract was efficient, the effect was lower than that of the tested fungicide. This work allows to infer that extracts of Piper sp. presented significant activities against the fungi Rhizoctonia solani and Sclerotium rolfsii. Further testing will be performed to verify its in vivo efficiency (field).

Keywords: Extracts; Fungitoxic Activity; Phytopathogens.
\end{abstract}

\section{lasmin Sousa (iD)}

Universidade Federal de Viçosa, Brasil

http://orcid.org/0000-0001-6076-3024 iasminp.sousa@gmail.com

\section{Cleberson de Freitas Fernandes}

Universidade Federal do Ceará, Brasil

http://lattes.cnpq.br/7426209328649448

cleberson.fernandes@embrapa.br

José Roberto Vieira Junior (iD

Universidade Federal de Viçosa, Brasil

http://lattes.cnpq.br/9904275274067824

http://orcid.org/0000-0001-7939-8119

jose-roberto.vieira@embrapa.br
Deizieny Silva

Universidade Federal de Viçosa, Brasil

deizienya@gmail.com

Taciára Letícia Oliveira Mendes (i)

Faculdades Integradas Aparício Carvalho, Brasil http://lattes.cnpq.br/0470801546385003 http://orcid.org/0000-0003-1908-0330

taciaramendes@gmail.com

\section{Tamiris Chaves Freire}

Universidade Federal de Rondônia, Brasil

http://lattes.cnpq.br/4372408393666360

http://orcid.org/0000-0002-8938-3751

tamirischavesfreire@gmail.com
Aline Souza da Fonseca (D)

Universidade Federal de Rondônia, Brasil http://orcid.org/0000-0002-4019-3412 alinesouzadafonseca@gmail.com

\section{Simone Carvalho Sangi (it)}

Universidade Federal de Rondônia, Brasil http://lattes.cnpq.br/6013814953613677 http://orcid.org/0000-0001-7365-015X simonecarvalhosangi@gmail.com

\section{Referencing this:}

SOUSA, I.; FERNANDES, C. F.; VIEIRA JUNIOR, J. R.; SILVA, D.; MENDES, T. L. O.; FREIRE, T. C.; FONSECA, A. S.; SANGI, S. C.. Atividade fungitóxica de extratos de Piper sp. contra os fungos Rhizoctonia solani e Sclerotium rolfsii. Revista Ibero Americana de Ciências Ambientais, v.9, n.3, p.50-56, 2018. DOI: http://doi.org/10.6008/CBPC2179-6858.2018.003.0005 


\section{INTRODUÇÃO}

No Brasil o feijão comum (Phaseolus vulgaris L.) é um dos alimentos mais populares fazendo parte da dieta alimentar de toda a população. É um alimento que possui propriedades nutricionais e funcionais capazes de atender muitas necessidades básicas da alimentação humana destacando-se, principalmente, como fonte protéica, no entanto, seu cultivo enfrenta sérios problemas fitossanitários que limitam sua produtividade, sendo importante, neste contexto, as pragas e doenças (GONÇALVES et al., 2015).

Uma das doenças mais importantes nessa cultura são conhecidas como podridões radiculares do feijoeiro (CASA et al., 2011) também denominado mela, causada pelo fungo necrotrófico Rhizoctonia solani Khun (teleomorfo Thanatephorus cucumeris) (FIALLOS, 2011), sendo um fungo patogênico de solo podendo matar a planta antes da formação das infrutescências, provocando redução de até $100 \%$ no rendimento de grãos (CASA et al., 2011).

O fungo Sclerotium rolfsii Sacc. é responsável por podridões do colo e raízes, murcha e tombamento de plântulas, em inúmeras espécies economicamente importantes, dentre as quais, o feijoeiro (BOSAH et al., 2010; AULER et al., 2013). Trata-se de um patógeno de difícil controle, pois forma escleródios de cerca de $1 \mathrm{~mm}$ de diâmetro, de cor branca a castanha, que lhe confere a capacidade de sobreviver por longos períodos no solo em condições adversas (YAQUB et al., 2011; AULER et al., 2013).

Desta forma, a busca por métodos alternativos de controle de doenças que causem menos impacto ao meio ambiente e seja eficiente no manejo de doenças vem crescendo (CELOTO et al., 2008), principalmente por ocorrer o uso indiscriminado e recorrente de fungicidas sintéticos, o que pode gerar o aparecimento de cepas resistentes, acúmulo de resíduos tóxicos em produtos agrícolas e poluição ambiental (PÉREZ et al., 2011).

Os extratos de plantas são uma opção para o controle, agindo como fungicidas ou como reguladores de crescimento de fungos patogênicos. A utilização de extratos para o combate de fungos no contexto da agricultura sustentável é uma alternativa promissora, porque os compostos obtidos a partir de plantas são biodegradáveis, altamente eficazes, de baixo custo e não poluem o meio ambiente (MARTínEZ et al., 2010; MOO-KOH et al., 2014). E por algumas plantas apresentarem uma diversidade de substâncias em sua composição, muitas vezes com potencial fungicida ou fungistático, devem ser estudadas para serem utilizadas diretamente pelo produtor, bem como servir de matéria-prima para síntese de novos fungicidas (CELOTO et al., 2008).

Portanto, estudos que procurem identificar compostos alternativos que apresentem potencial de controle para agentes fitopatogênicos e que minimizem possíveis efeitos adversos à saúde do aplicador e ao meio ambiente possuem grande importância. Neste sentido, o presente estudo objetivou verificar o uso de extratos vegetais com potencial bioativo no controle de fitopatógenos de importância para a cultura do feijoeiro, como os fungos Rhizoctonia solani e Sclerotium rolfsii. 


\section{MATERIAIS E MÉTODOS}

Os ensaios foram conduzidos no Laboratório de Fitopatologia da Embrapa Rondônia. Os materiais vegetais sendo folha e talo de Piper sp. foram coletados na casa de vegetação da Embrapa Rondônia. Para obtenção dos extratos vegetais de folhas, estas foram inicialmente maceradas em nitrogênio líquido até formação de um fino pó. Em seguida, $10 \mathrm{~g}$ do tecido vegetal foi submetido a extração em tampão PBS 0,1 M, pH 7,4, na proporção de 1:10 (g/mL). A suspensão foi submetida a agitação em mesa orbital agitadora por 24 horas, $100 \mathrm{rpm}, 25{ }^{\circ} \mathrm{C}$. Em seguida o material foi filtrado em pano de nylon de trama fina, centrifugado (13000 rpm a $4^{\circ} \mathrm{C}$ por 20 minutos), e o sobrenadante foi acondicionado a $8{ }^{\circ} \mathrm{C}$ para realização das análises laboratoriais.

Para a obtenção do extrato vegetal de talo, este foi inicialmente conduzido à estufa por 48 horas, e após este período, triturado em moinho de bolas até formação de um fino pó. A partir daí o preparo do extrato foi realizado conforme descrito anteriormente (SOUZA, 2004; FREIRE, 2015) adaptado. Os isolados fúngicos de Rhizoctonia solani e Sclerotium rolfsii utilizados na pesquisa foram retirados a partir de culturas puras da coleção do laboratório de fitopatologia da Embrapa Rondônia, os quais foram mantidas em meio BDA.

Para a realização dos ensaios de atividade fungitóxica (Atividade Antifúngica in vitro), os extratos foram homogeneizados ao meio BDA semissólido fundente, de modo a obter uma concentração de 10\%, e vertidos em placas de Petri. Posteriormente à solidificação do BDA, foram transferidos no centro das placas, discos de $0,5 \mathrm{~cm}$ de diâmetro do micélio dos fitopatógenos. As placas de Petri foram incubadas em câmara BOD a uma temperatura de 25 ํㅡ, com fotoperíodo de 12 horas (VENTUROSO et al., 2011) adaptado. Os controles utilizados no experimento foram tampão PBS (0,1 M) e o fungicida Amistar (0,6 g/L).

Para cada microrganismo, foram avaliados 16 tratamentos, sendo 4 repetições para cada (Extratos talo e folha, Fungicida e Solução tampão PBS). As avaliações foram realizadas diariamente, a partir do segundo dia de incubação, nas quais foram feitas medições do halo de crescimento dos fungos, por meio de um paquímetro, até a medição das placas que continham o grupo controle com PBS atingissem a borda das mesmas.

Para os ensaios em casa de vegetação (Atividade Antifúngica in vivo) com R. solani e S. rolfsii foram utilizadas plantas de feijoeiro com 14 dias de plantio. As plantas foram inoculadas com uma suspensão de fragmentos de micélios do patógeno $\left(1 \times 10^{6}\right.$ frag.micélios $\left./ \mathrm{mL}\right)$ e disco de micélio de $0,5 \mathrm{~cm}$ de diâmetro do patógeno, respectivamente. Para avaliação de controle do patógeno, primeiramente aplicou-se a suspensão fúngica e os discos e depois os tratamentos com 100, 50, 25, 12,5, 6,25 e 3,125 mg/mL de extrato bruto de Piper sp. Tratamentos controle com tampão PBS 0,1 M, e os fungicidas Amistar (R. solani) e Vitavax (S. rolfsii) foram preparados. Cada tratamento continha cinco repetições. 


\section{RESULTADOS E DISCUSSÃO}

Após as avaliações pode-se verificar a inibição dos fitopatógenos (Tabela 1 e 2) sendo utilizados extratos de Piper, folha e talo nas concentrações de $1 / 10(\mathrm{~g} / \mathrm{mL})$. Foram utilizados como controle positivo o fungicida Amistar tendo em sua composição (azoxistrobina) e controle negativo a solução tampão PBS. Para o fungo Rhizoctonia solani, ambos os extratos de Piper sp., folha e talo, apresentaram atividade de inibição do crescimento fúngico, com percentual de inibição de cerca de $3 x$ superior ao observado com o controle positivo (Figura 1).

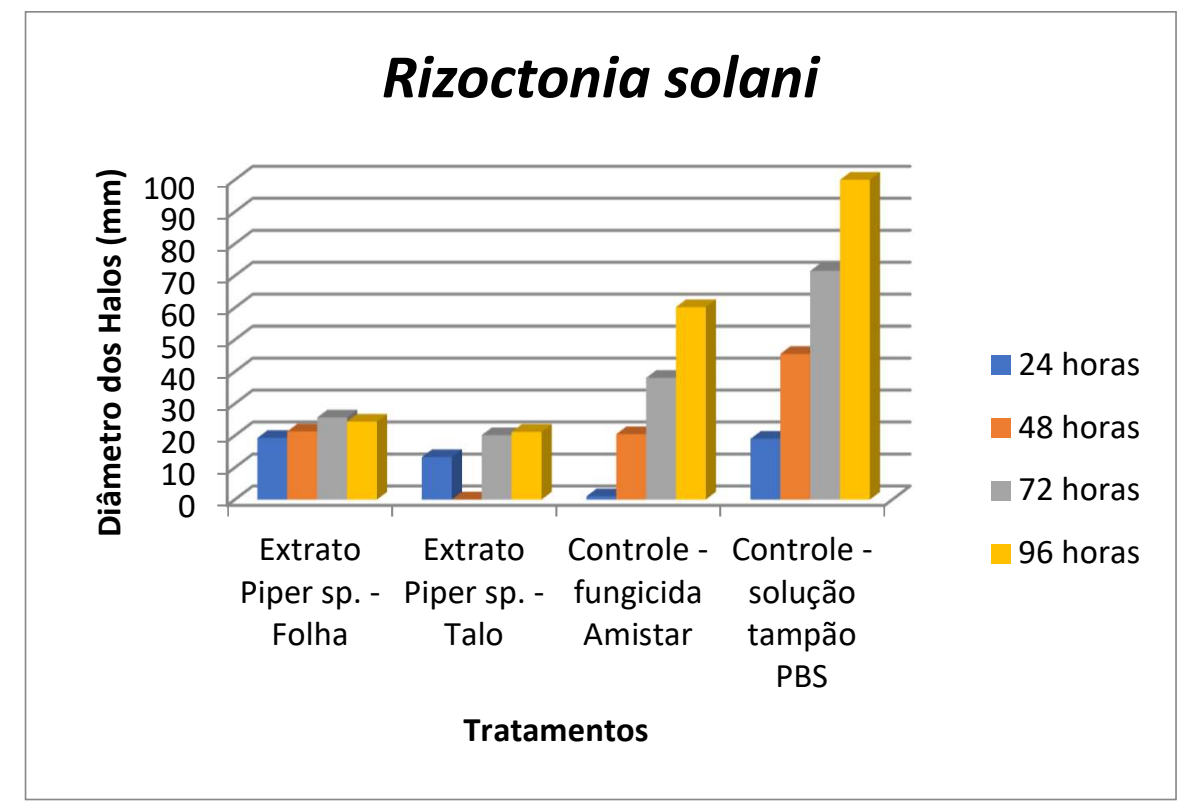

Figura 1: Halo de crescimento de Rhizoctonia solani na presença de extratos de Piper sp.

Para o fungo Sclerotium rolfsii, ambos os extratos de Piper sp., folha e talo, apresentaram atividade de inibição do crescimento fúngico, com percentual de inibição semelhante ao observado com o controle positivo (Figura 2).

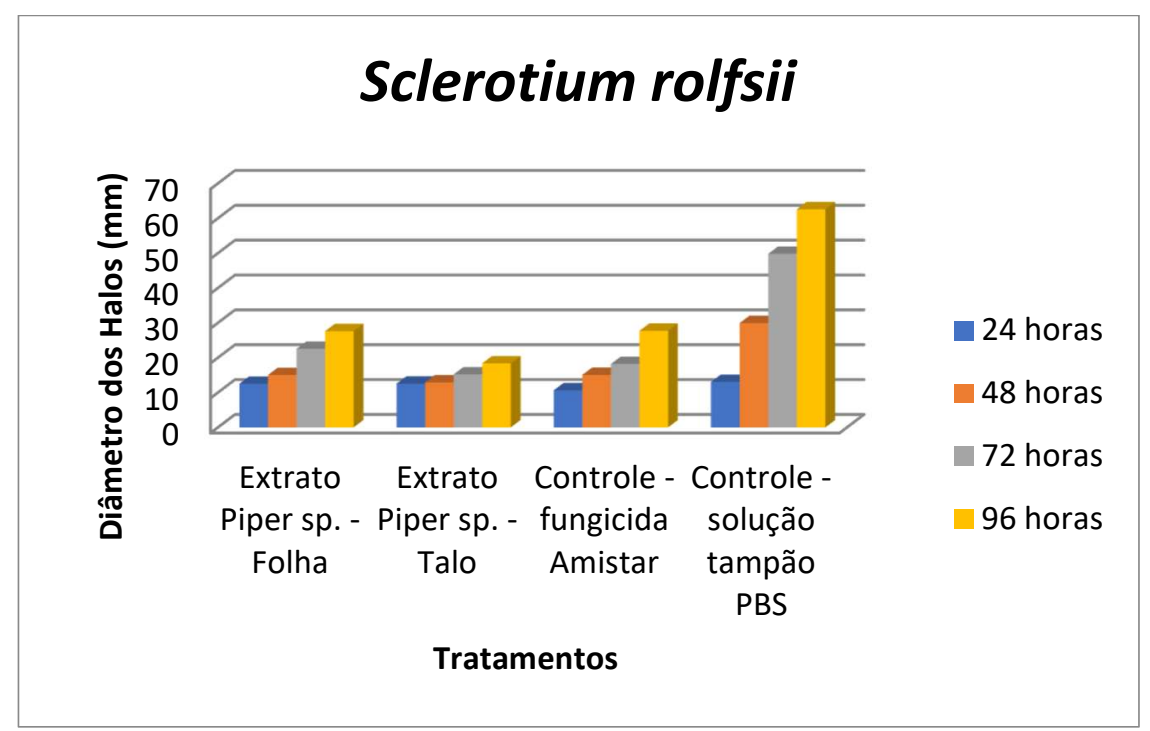

Figura 2: Halo de crescimento de Sclerotium rolfsii na presença de extratos de Piper sp. 
As avaliações das atividades antifúngicas in vivo foram conduzidas em mudas de feijoeiro inoculadas com os dois fitopatógenos. Os resultados obtidos não mostraram diferenças significativas entre eles, nas concentrações avaliadas, 15 dias após a inoculação dos patógenos. Para o fungo $R$. solani, os extratos de talo apresentaram menores valores médias de severidade, quando comparado com os extratos de folha (Figura 3). Entretanto, os valores médios de severidade para o fungicida foram melhores em todas as concentrações avaliadas. Também para o fungo S. rolfsii, os valores médios de severidade foram menores nos extratos de talos, quando comparados com os extratos de folha (Figura 4). Também aqui, a severidade para o tratamento com fungicida foi menor do que para com os extratos em ambos os casos.

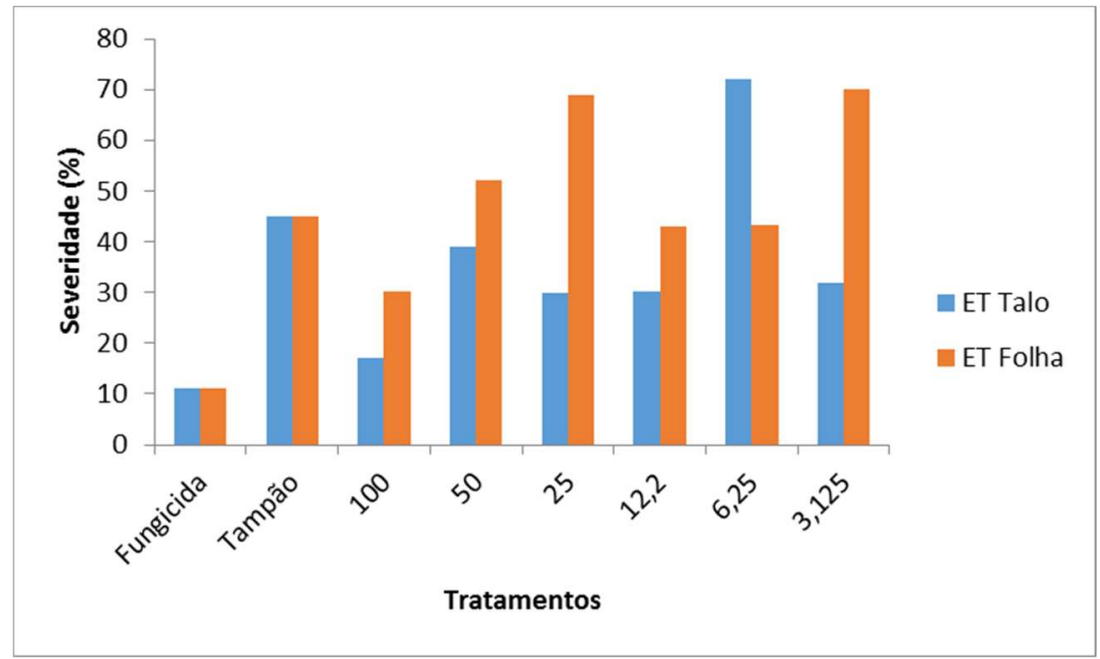

Figura 3: Percentual de severidade da doença por Rhizoctonia solani na presença de extratos de Piper sp.

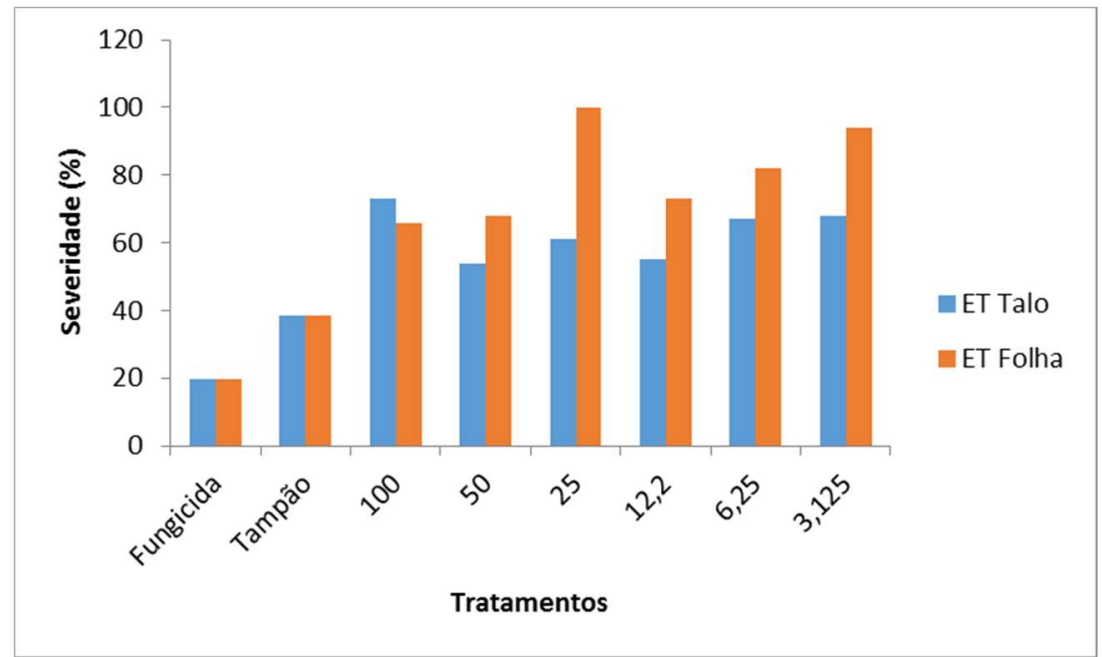

Figura 4: Percentual de severidade da doença por Sclerotium rolfsii na presença de extratos de Piper sp.

Segundo Celoto et al. (2008), para se obter um produto que seja viável a recomendação aos produtores ou a síntese de nova molécula fungicida, existe necessidade de pesquisa que procure detectar onde estão essas substâncias, tendo como hipótese que extratos de plantas de nossa flora têm propriedades antimicrobianas. Um exemplo disso são as plantas do gênero Piper sendo de interesse à farmacologia devido à grande variedade de metabólitos secundários que apresentam (alcalóides, flavonóides, arilpropanóides e lignanas) (JUDD et al., 2002; FACUNDO, 2008; SANTANA, 2012). 
O emprego dos extratos vegetais é bastante conhecido, caso do extrato de camomila que inibiu $52 \%$ o crescimento micelial de Fusarium sp. e o fungo Botrytis sp. que foi inibido com os extratos de alecrim, eucalipto e menta e o cravo-da-índia controlou $100 \%$ o crescimento micelial de C. gloeosporioides, F. oxysporum f.sp. vasinfectum e $P$. oryzae (CAMATTI-SARTORI et al., 2011; SILVA et al., 2012).

Medeiros et al. (2012) e Rodrigues et al. (2014) também verificaram que houve diferenças nos controles entre as diferentes partes das plantas testadas, tanto para o controle de Fusarium oxysporum como para o pulgão preto. Isso provavelmente se deve ao fato de existirem diferentes constituintes e em diferentes concentrações em todas as partes das plantas, podendo variar da espécie da planta, parte utilizada, finalidade, localização geográfica, sazonalidade, idade fisiológica da planta e época de colheita (FACUNDO et al., 2008; MEDEIROS et al., 2012; MORALESA, et al., 2013; RODRIGUES et al., 2014).

Silva et al. (2007) obteve resultados que demonstraram que os óleos essenciais de Piper callosum, Piper marginatum var. anisatum e Piper enckea tiveram ação fungitóxica significativa contra três fitopatógenos testados, sendo eles Crinipellis perniciosa, Phytophthora palmivora e Phytophthora capsici. Stangarlin (2007) demonstrou que pimenta longa apresentou efeito inibitório inferior a $50 \%$ no crescimento do fitopatógeno $S$. sclerotiorum. Freire (2015) testou os extratos etanólicos de talos de $P$. tuberculatum, onde o mesmo apresentou eficiência no controle in vitro de $R$. solani e $S$. rolfsii.

\section{CONCLUSÕES}

Os testes permitem inferir que extratos de Piper sp. apresentaram atividades fungitóxicas significativas contra os fungos Rhizoctonia solani e Sclerotium rolfsii, demonstrando sua eficácia in vitro, entretanto, esta atividade não se repetiu nos ensaios em casa de vegetação.

AGRADECIMENTOS: Este estudo foi apoiado pelo Conselho Nacional de Desenvolvimento Científico e Tecnológico (CNPq) através do projeto para CFF - Número do subsídio 485047/2013-6, Financiadora de Estudos e Projetos (FINEP), Fundação Rondônia de Amparo ao Desenvolvimento das Ações Científicas e Tecnológicas e de Pesquisa do Estado de Rondônia (FAPERO). Agradecimentos a Domingos Sávio G. Silva e Antônio M. Marques pela assistência técnica. Sousa, IP agradece a FAPER/CAPES pela Bolsa de Iniciação Científica. Os autores agradecem a Coordenação de Aperfeiçoamento de Pessoal de Nível Superior (CAPES) pelas Bolsas de Pós-Graduação. Os financiadores não tiveram papel em design de estudo, coleta e análise de dados, decisão de publicação ou preparação do manuscrito.

\section{REFERÊNCIAS}

AULER, A. C. V.; CARVALHO, D. D. C.; MELLO, S. C. M.. Antagonismo de Trichoderma harzianum a Sclerotium rolfsii nas culturas do feijoeiro e soja. Revista Agro Ambiente, v.7, n.3, p.359-365,2013.

CAMATTI-SARTORI, V.; MAGRINI, F. E.; CRIPPA, L. B.; MARCHETT, C.; VENTURIN, L.; SILVA-RIBEIRO, R. T.. Avaliação in vitro de extratos vegetais para o controle de fungos patogênicos de flores. Revista Brasileira de Agroecologia. v.6, n.2, p.117-122, 2011.

CASA, R. T.; KRIEGER, I.; JUNIOR, P. R. K.; BOGO, A.; MOREIRA, E. N.; RIZZI, F. P.. Podridão radicular em feijão no sistema plantio direto. Revista de Ciências Agroveterinárias. Lages, v.10, n.1, p.37-43, 2011. 
CELOTO, M. I. B.; PAPA, M. F. S.; SACRAMENTO, L. V. S.; CELOTO, F. J.. Atividade antifúngica de extratos de plantas a Colletotrichum gloeosporioides. Acta Scientiarum Agronomy, Maringá, v.30, n.1, p.1-5, 2008.

FACUNDO, V. A.; POLLI, A. L.; RODRIGUES, R. V.; MILITÃO, J. S. L. T.; STABELLI, R. G.; CARDOSO, C. T.. Constituintes químicos fixos e voláteis dos talos e frutos de Piper tuberculatum Jacq. e das raízes de P. hispidum H. B. K. Acta Amazônica, v.38, n.4, p.733-742, 2008.

FIALLOS, F. R. G.. Modelo de ponto crítico para estimar danos causados pela mela na cultura do feijoeiro. Quito: Ciencia y Tecnología, 2011.

FREIRE, T. C.. Extrato vegetal de Piper com potencial atividade antifúngica contra Rhizoctonia solani e Sclerotium rolfsii. Dissertação (Mestrado em Ciências Ambientais) - Fundação Universidade Federal de Rondônia, Rolim de Moura, 2015.

GONÇALVES, A. H.; PEREIRA, A. S.; SANTOS, G. R. S.; GUIMARÃES, L. G. L.. Atividade fungitóxica in vitro dos óleos essenciais de Lippia sidoides Cham., Cymbopogon citratus (D.C.) Stapf. e de seus constituintes majoritários no controle de Rhizoctonia solani e Sclerotium rolfsii. Revista Brasileira de Plantas Medicinais, Campinas, v.17, n.4, p.1007-1015. DOI: http://dx.doi.org/10.1590/1983-084x/14 166

JUDD, W. S.; CAMPBELL, C. S.; KELLOGG, E. A.; STEVENS, P. F.; DONOGHUE, M. J.. Plant Systematics: a phylogenetic approach. 2 ed. Sunderland: Sinauer associates, 2002.

MARTÍNEZ, S.; TERRAZAS, E.; ALVAREZ, T.; MAMANI, O. ; VILAA, J.; MOLLINEDO P.. Actividad antifungica in vitro de extractos polares de plantas del género Baccharis sobre fitopatógenos. Rev. Boliv. Quím., v.27, n.1, p.13-18, 2010.

MEDEIROS, E. V.; VIANA, M. G.; ALBUQUERQUE, C. C.; VIANA, F. A.; SILVA, K. M. B.. Extrato etanólico de Senna alata no controle de Fusarium oxysporum, causador da murcha-de-fusarium do meloeiro. Revista Brasileira de Engenharia Agrícola e Ambiental, v.16, n.11, p.1166-1170, 2012.

MOO-KOH, F. A.; ALEJO, J. C.; REYES-RAMÍREZ, A.; TUNSUÁREZ, J. M.; SANDOVAL-LUNA, R.; RAMÍREZ-POOL J. A.. Actividad in vitro del extracto acuoso del Bonellia flammea contra hongos fitopatógenos.

Agrociencia, v.48, n.8, p.833-845, 2014.

MORALESA, A.; ROJASA, J.; MOUJIRB, L. M.; ARAUJOB, L.; RONDÓNC, M.. Chemical composition, antimicrobial and cytotoxic activities of Piper hispidum Sw. essential oil collected in Venezuela. Journal of Applied Pharmaceutical Science, v.3, n.6, p. 016-020, 2013.

PÉREZ, A. C.; SIERRA, J. R.; CHAMORRO L. A.; PÉREZ, K. P Evaluación de la actividad antifúngica de Melia azederach sobre aislados de Colletotrichum spp. Rev. Colomb. Ciencia Anim., v.3, n.2, p.309-320, 2011.

RODRIGUES, V. M.; VALENTE, E. C. N.; LIMA, H. M. A TRINDADE, R. C. P.; DUARTE, A. G.. Avaliação de extratos de Annona muricata L. sobre Aphis craccivora Koch, 1854 (Hemiptera: Aphididae). Revista Brasileira de Agroecologia, v.9, n.3, p.75-83, 2014.

SANTANA, H. T.. Estudo fitoquímico de Piper alatabaccum trel \& yunck, 1950 e avaliação da atividade larvicida sobre Aedes aegypti linnaus, 1762 (diptera: culicidae) em condições de campo simulado. Dissertação (Mestrado em Biologia Experimental) - Fundação Universidade Federal de Rondônia, Porto Velho, 2012.

SILVA, D. M. M. H.; BASTOS, C. N.. Atividade Antifúngica de Óleos Essenciais de Espécies de Piper sobre Crinipellis perniciosa, Phytophthora palmivora e Phytophthora capsici. Marituba: Fitopatologia Brasileira, 2007.

SILVA, J. L.; TEIXEIRA, R. N. V.; SANTOS, D. I. P.; PESSOA, J. O.. Atividade antifúngica de extratos vegetais sobre o crescimento in vitro de fitopatógenos. Revista Verde, Mossoró, v.7, n.1, p.80-86, 2012.

SOUZA, A. P.. Atividade inseticida e modo de extração de Meliáceas sobre Bemista tabaci (GENN, 1889) biótipo B. Tese (Doutorado em Ciências) - Universidade de São Paulo, São Paulo, 2004.

STANGARLIN, J. R.. Uso de extratos vegetais e óleos essenciais no controle de doenças de plantas. In: CONGRESSO BRASILEIRO DE FITOPATOLOGIA, 40. Anais. Maringá: Sociedade Brasileira de Fitopatologia, 2007. p.9495.

VENTUROSO, L. R.; BACCHI, L. M. A.; GAVASSONI, W. L.. Atividade antifúngica de extratos vegetais sobre $o$ desenvolvimento de fitopatógenos. Summa Phytopathologica, v.37, n.1, p.18-23, 2011.

YAQUB, F.; SHAHZAD, S.. Efficacy and persistence of microbial antagonists against Sclerotium rolfsii under field conditions. Pakistan Journal of Botany, v.43, n.5, p.26272634, 2011.

A CBPC - Companhia Brasileira de Produção Científica (CNPJ: 11.221.422/0001-03) detém os direitos materiais desta publicação. Os direitos referem-se à publicação do trabalho em qualquer parte do mundo, incluindo os direitos às renovações, expansões e disseminações da contribuição, bem como outros direitos subsidiários. Todos os trabalhos publicados eletronicamente poderão posteriormente ser publicados em coletâneas impressas sob coordenação da Sustenere Publishing, da Companhia Brasileira de Produção Científica e seus parceiros autorizados. Os (as) autores (as) preservam os direitos autorais, mas não têm permissão para a publicação da contribuição em outro meio, impresso ou digital, em português ou em tradução. 